\title{
Patogenicidade e caracterização de Thielaviopsis ethacetica em palma de óleo
}

\author{
Silvia Mara Coelho do Nascimento® ${ }^{1}$; Alessandra Keiko Nakasone@ ${ }^{2}$; Cândido Ferreira de Oliveira Neto® ${ }^{1}$; \\ Kézia Ferreira Alves ${ }^{3}{ }^{3}$; Rayanne Savina Alencar Sobrinho® ${ }^{1}$; Susana Silva Conceição@ ${ }^{1}$; \\ Kátia Regina de Andrade Campos ${ }^{1}$; Eudes de Arruda Carvalho ${ }^{4}$
}

\begin{abstract}
${ }^{1}$ Universidade Federal Rural da Amazônia, 66077-830, Belém-PA, Brasil. ²Empresa Brasileira de Pesquisa Agropecuária, Embrapa Amazônia Oriental, 66095-903, Belém-PA, Brasil. ${ }^{3}$ Instituto Federal de Educação, Ciência e Tecnologia do Pará, 68740-970, Castanhal-PA, Brasil. ${ }^{4}$ Embrapa Quarentena Vegetal, 70770-901, Brasília-DF, Brasil.
\end{abstract}

Autor para correspondência: Silvia Mara Coelho do Nascimento (silviamaracoelho@gmail.com)

Data de chegada: 21/03/2018. Aceito para publicação em: 19/12/2019.

$10.1590 / 0100-5405 / 193244$

\section{RESUMO}

Nascimento, S.M.C.; Nakasone, A.K.; Oliveira Neto, C.F.; Alves, K.F.; Alencar Sobrinho, R.S.; Conceição, S.S.; Campos, K.R.A.; Carvalho, E.A. Patogenicidade e caracterização de Thielaviopsis ethacetica em palma de óleo. Summa Phytopathologica, v.46, n.3, p.236-241, 2020.

Thielaviopsis paradoxa é fungo do solo, patógeno amplamente distribuído em todo o mundo e capaz de infectar uma ampla gama de hospedeiros. Em palma de óleo é o agente etiológico da podridão basal, uma importante doença que pode causar sérios prejuízos devido à sua severidade e à rápida dispersão do patógeno. $\mathrm{O}$ trabalho teve como objetivo avaliar a patogenicidade e caracterizar um isolado de Thielaviopsis sp. em palma de óleo. O isolado de Thielaviopsis sp. foi obtido do estipe de plantas de palma de óleo, com aparentes sintomas de podridão. A patogenicidade foi avaliada em duas cultivares de palma de óleo, o híbrido interespecífico Manicoré e o híbrido intraespecífico Tenera. As mudas foram inoculadas por suspensão de conídios na concentração de $1 \times 10^{7}$ conídios por mililitro e discos de micélios, com e sem ferimentos na ráquis de folhas. $\mathrm{O}$ isolado foi cultivado em meio de cultura BDA para a caracterização morfológica. A análise filogenética foi realizada com base em comparação de sequências das regiões EF-1 $\alpha$ e ITS com sequências disponíveis no GenBankNCBI e analisadas no Mega 6.0. O isolado foi patogênico nas duas cultivares da palma de óleo em mudas previamente feridas, causando sintomas de podridão de coloração marrom, com formação de um halo amarelado na ráquis. Com o progresso da doença, as folhas apresentaram coloração amarelo progredindo para seca até a quebra da ráquis. $\mathrm{O}$ isolado de Thielaviopsis $\mathrm{sp}$. apresentou crescimento rápido com velocidade de crescimento micelial de $50,76 \mathrm{~mm} \mathrm{dia}^{-1}$ e com dois dias ocupou totalmente a placa de Petri de $90 \mathrm{~mm}$. A colônia, de coloração inicialmente branca, tornou-se negra com a esporulação e produção de dois tipos de conídios: os endoconídios e aleuroconídios. Após as análises filogenéticas, foi possível comprovar a espécie Thielaviopsis ethacetica como agente etiológico da podridão basal da palma de óleo, distinguindo-a da espécie T. paradoxa.

Palavras-chave: Thielaviopsis ethacetica; Filogenia; Elaies spp.

\section{ABSTRACT}

Nascimento, S.M.C.; Nakasone, A.K.; Oliveira Neto, C.F.; Alves, K.F.; Alencar Sobrinho, R.S.; Conceição, S.S.; Campos, K.R.A.; Carvalho, E.A. Pathogenicity and characterization of Thielaviopsis ethacetica in oil palm. Summa Phytopathologica, v.46, n.3, p.236-241, 2020.

Thielaviopsis paradoxa is a soilborne fungal pathogen widely distributed worldwide and capable of infecting a wide range of hosts. In oil palm, it is the etiological agent of basal rot, an important disease that can cause serious damage due to its severity and the rapid dispersion of the pathogen. This study evaluated the pathogenicity and characterized an isolate of Thielaviopsis sp. in oil palm. The isolate was obtained from the stem of an oil palm plant with apparent rot symptoms. Pathogenicity was evaluated in two oil palm cultivars, the interspecific hybrid Manicoré and the intraspecific hybrid Tenera. Seedlings were inoculated by conidial suspension at $1 \times 10^{7}$ conidia per milliliter e mycelial disks, with and without injuries in the leaf rachis. The isolate was grown in PDA culture medium for morphological characterization. Phylogenetic analysis was performed based on comparison of sequences from the EF-1 $\alpha$ and ITS regions with sequences available from GenBank-NCBI and analyzed in Mega 6.0. The isolate was pathogenic to the two oil palm cultivars in previously injured seedlings, causing symptoms of brown rot and formation of a yellowish halo in the rachis. As the disease progressed, the leaves showed yellow coloration and dried, resulting in broken rachis. The isolate of Thielaviopsis sp. showed rapid growth with mycelial growth rate of $50.76 \mathrm{~mm} \mathrm{day}^{-1}$, covering the 90-mm Petri plate within two days. The colony, initially white, became black with sporulation and produced two types of conidia: endoconidia and aleuroconidia. After phylogenetic analyses, the species Thielaviopsis ethacetica could be proven as the etiological agent of the dry basal rot of oil palm and could be distinguished from $T$. paradoxa.

Keywords: Thielaviopsis ethacetica; Phylogeny; Elaies spp.

A palma de óleo é considerada uma das oleaginosas mais promissoras para o agronegócio em âmbito global (10). A Indonésia e a Malásia são os principais produtores, compreendendo $85 \%$ de toda produção mundial $(19,22)$. O Brasil apresenta enorme capacidade produtiva, com disponibilidade de áreas para expansão dos cultivos, notadamente na região amazônica $(9,13)$. O estado do Pará é o maior produtor com uma área plantada de 140 mil hectares, com produção anual de 770 mil toneladas de óleo de palma, o que corresponde a $90 \%$ da produção do país (4).

No entanto, a cultura é acometida por diversos problemas fitossanitários que podem refletir na produtividade e no aumento dos custos de produção (6). Dentre os fitopatógenos, principalmente de 
origem fúngica, destaca-se o fungo Thielaviopsis paradoxa, agente etiológico da podridão basal da palma de óleo $(1,25)$.

Thielaviopsis paradoxa é considerado um patógeno agressivo e de difícil controle, que infecta monocotiledôneas, sobrevive no solo por longos períodos e em restos de culturas em decomposição, sendo associado às doenças de plantas com algum tipo estresse como déficit hídrico e deficiência nutricional $(1,21,27)$. Pode ser dispersado pela chuva, vento, insetos ou por ferimento e ferramentas usadas na colheita, tratos culturais ou erradicação de plantas doentes $(1,27)$. Thielaviopsis paradoxa é a fase assexual do patógeno, sendo responsável pela produção de dois tipos de esporos, os endoconídios e os clamidósporos. Em sua fase sexual é denominado de Ceratocystis paradoxa (Dade) C Moreau $(1,27)$.

A podridão basal do estipe constitui risco adicional à palma de óleo e pode causar sérios prejuízos devido à sua severidade e a rápida disseminação. As áreas susceptíveis à ocorrência da podridão basal apresentam comprometimento da produção, em função do apodrecimento dos tecidos, amarelecimento dos folíolos do pecíolo, secamento e quebra das folhas reduzindo, consequentemente, a sustentação dos cachos provocando queda de frutos imaturos ou morte da planta $(16,25)$.

A doença encontra-se distribuída em grande parte das principais regiões produtoras do Brasil e do mundo, sendo relatadas perdas econômicas em diversos países. Na Nigéria, causou sérios danos ao plantio, devido à podridão na base do estipe e morte de plantas (25). No Equador, provocou grandes danos à produção (8). Na Colômbia causou graves danos aos plantios de palma de óleo, com perdas de até $70 \%$ das plantações (27). No Brasil, a ocorrência da doença já foi relatada nos estados do Pará $(3,5)$ e da Bahia (18). Além da palma de óleo, o patógeno apresenta ampla gama de hospedeiros, incluindo espécies de importância econômica, como na cultura do coqueiro (28), bananeira (2), abacaxizeiro (12) e cana-de-açúcar (7).

Entretanto, a partir de estudos de isolados da palma de óleo, cacau e abacaxi, da região de Camarões na África, através de sequência do DNA, análises morfológicas e filogenéticas do complexo Ceratocystis paradoxa, uma redefinição taxonômica, onde o agente etiológico responsável pela podridão basal, e de várias doenças em ampla gama de hospedeiro foi denominado de Thielaviopsis ethacetica na fase anamórfica e Ceratocystis ethacetica compreende a fase teleomórfica $(11,17)$.

O fungo Thielaviopsis ethacetica Went. foi relatado pela primeira vez em 1924 (DADE, 1928), originalmente descrito em Java, como agente etiológico da podridão do abacaxi da cana de açúcar (29). Sendo posteriormente reavaliado e descrito como sinônimo de Thielaviopsis paradoxa (De Seynes) Höhn, baseado na similaridade morfológica entre os dois fungos (14).

Segundo Mbenoun et al. (17), T. ethacetica e T. paradoxa, são patógenos diferentes que apresentam morfologias semelhantes. Entretanto, conforme os autores, há uma grande diversidade genética no gênero Thielaviopsis, de modo que as espécies apresentam similaridade morfológica e são filogeneticamente diferentes. Estudos envolvendo a interação entre os fungos T. ethacetica ou T. paradoxa e palma de óleo, são ainda escassos no Brasil. Sendo assim, a identificação correta do patógeno prevalecente nos plantios de palma de óleo e o esclarecimento baseado nos testes de patogenicidade e métodos de inoculações, são importantes na identificação da sintomatologia e caracterização das relações patógeno-hospedeiro.

Dessa forma, diante da importância econômica da cultura da palma de óleo, e da reclassificação da espécie em outros patossistemas no mundo, o objetivo desta pesquisa foi avaliar a patogenicidade e caracterizar um isolado de Thielaviopsis sp. em palma de óleo.

\section{MATERIAL E MÉTODOS}

Os experimentos foram conduzidos no Laboratório de Fitopatologia da Embrapa Amazônia Oriental.

\section{Isolamento do fungo e teste de patogenicidade}

O isolado de Thielaviopsis sp. foi obtido a partir de plantas sintomáticas de podridões em tecidos internos do estipe e na base da folha flecha em palma de óleo. $O$ teste de patogenicidade foi conduzido em mudas do híbrido interespecífico - HIE BRS Manicoré e do híbrido intraespecífico Tenera, com 2 e 1,5 anos de idade, respectivamente. Realizou-se a inoculação com suspensão de conídios a $1 \times 10^{7}$ conídios $\mathrm{mL}^{-1}$ e por discos de micélio na ráquis de folhas, com e sem ferimento prévio (Figura 1). Cada ponto de inoculação foi envolvido com parafilme por 72 horas e as mudas mantidas em casa de vegetação sob temperatura média de $28{ }^{\circ} \mathrm{C}$ e umidade relativa do ar média de $95 \%$.

Adotou-se delineamento experimental inteiramente ao acaso com 10 repetições. Os tratamentos controle constituíram-se de plantas de cada híbrido, com e sem ferimento, porém não inoculadas. Foi determinado o Período de Incubação (PI), sendo observado o tempo em dias, decorrido desde a inoculação do patógeno até o aparecimento dos primeiros sintomas da doença.

\section{Mensuração do crescimento micelial e avaliações de características morfológicas}

O crescimento micelial e as características morfológicas do fungo foram avaliados in vitro. Para tanto, discos de micélio de $5 \mathrm{~mm}$ de diâmetro, de cultura cultivada por cinco dias, foram repicados para placas de Petri, contendo o meio de cultura Batata-Dextrose-Ágar(BDA) e incubados durante três dias em câmara de crescimento tipo BOD à temperatura de $28^{\circ} \mathrm{C}$ e fotoperíodo de $12 \mathrm{~h}$. Foram tomadas medidas do diâmetro da colônia em dois eixos perpendiculares marcados no fundo de cada placa. Calculou-se a velocidade de crescimento micelial (VCM), utilizando-se a equação descrita por Oliveira (24): $\mathrm{VCM}=\sum$ $((\mathrm{D}-\mathrm{Da}) / \mathrm{N})$, onde o $\mathrm{VCM}=$ velocidade de crescimento micelial; $\mathrm{D}=$ diâmetro médio atual da colônia; $\mathrm{Da}=$ diâmetro médio da colônia do dia anterior e $\mathrm{N}=$ número de dias após a inoculação. Outras características fúngicas como coloração da colônia também foram registradas. As dimensões dos conídios foram mensuradas por microscopia fotônica a partir de uma suspensão de inóculo preparada de colônias com cinco dias de incubação. Foram registrados o comprimento e largura de 100 conídios amostrados ao acaso em lâminas sob aumento de 40 vezes. Foram expressas as médias de comprimento e de largura, assim como registrados os limites superiores e inferiores de cada dimensão.

\section{Caracterização Molecular}

\section{Extração de DNA e análise filogenética}

Para a extração do DNA, utilizou-se uma colônia do isolado fúngico cultivada em meio de cultura batata dextrose-ágar (BDA) por cinco dias. A extração de DNA foi realizada utilizando-se o protocolo descrito por Joshi et al. (15), adaptado por Oliveira et al. (23).

As reações em cadeia de polimerase (PCR) foi realizada em um volume final de $50 \mu \mathrm{L}$ contendo $2 \mu \mathrm{L}$ do DNA fúngico, $10 \mu \mathrm{L}$ de tampão $5 \mathrm{X}, 6 \mu \mathrm{L}$ de $\mathrm{MgCl}_{2}, 0,5 \mu \mathrm{L}$ dos primers ITS4 e ITS5; EF1 e EF2 $1 \mu \mathrm{L}$ de $\mathrm{dNTP}, 0,3 \mu \mathrm{L}$ de Taq polimerase e $29,7 \mu \mathrm{L}$ de água ultra pura. As 

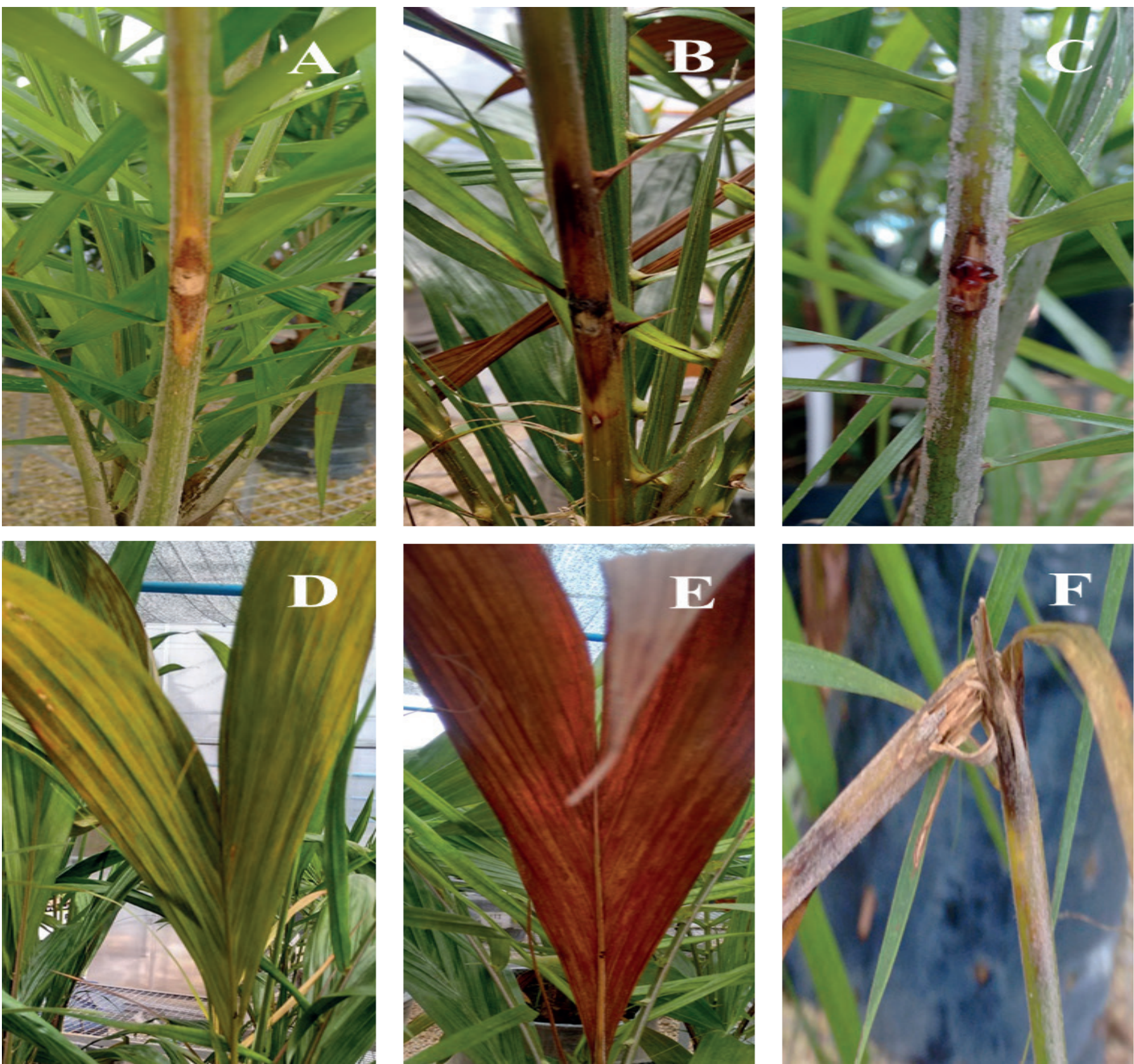

Figura 1. Sintomas da podridão basal em mudas de palma de óleo: Lesões necróticas marrom escuras (A, B); exsudação de resina (C); folhas amareladas que secavam e quebravam (D, E e F).

condições de amplificações foram de desnaturação inicial de $95^{\circ} \mathrm{C}$ por $95 \mathrm{~s}$, seguido de 35 ciclos de $95^{\circ}$ por $2 \mathrm{~min}, 58^{\circ} \mathrm{C}$ por $1 \mathrm{~min}$ e $72^{\circ}$ por $30 \mathrm{~s}$, com extensão final de $72^{\circ} \mathrm{C}$ por $10 \mathrm{~min}$. O produto do $\mathrm{PCR}$ foi avaliado em gel de agarose $0,8 \%$, corado com GelRed (Biotium) e fotodocumentado. Os produtos de PCR das regiões ITS e EF foram sequenciados pela empresa ACTGene. A análise filogenética foi realizada com base em comparação de sequências do gene EF-1 $\alpha$ e ITS com sequências disponíveis no GenBank-NCBI. As sequências foram avaliadas utilizando o programa Mega 6.0 As análises filogenéticas foram realizadas para a máxima parcimônia.

\section{RESULTADOS E DISCUSSÃO}

Foi isolado o fungo Thielaviopsis sp. associado às lesões necróticas do estipe da palma de óleo, sendo patogênico nas duas cultivares avaliadas. Todas as mudas, com ferimento prévio na ráquis, inoculadas por disco de micélio e suspensão de conídios manifestaram sintomas aos 5 dias após inoculação. No entanto, nas plantas sem ferimento e no tratamento controle não foram observados sintomas da podridão basal. O fungo não conseguiu infectar e colonizar o tecido no local inoculado, quando se utilizou o método sem ferimento. 
O resultado apresentado neste trabalho comprovou que, para ocorrer infecção por Thielaviopsis sp. em mudas de palma de óleo, são necessários ferimentos no tecido vegetal. $\mathrm{O}$ resultado corroborou com os resultados de Silva (26) quando em estudo a resinose do coqueiro, observou no teste de patogenicidade com T. paradoxa, em mudas de coqueiro, que a infeção ocorreu através de ferimento prévio na ráquis e que mudas inoculadas sem ferimento permaneceram sadias, sem sintoma da resinose do coqueiro. O fungo Thielaviopsis paradoxa é um patógeno que causa infeção através de ferimentos e das fissuras naturais (20), podendo disseminar-se principalmente através de insetos vetores (Rhynchophorus palmarum e Strategus aloeus), solo e ferramentas contaminadas (21). Conforme Alvarez et al. (1) e Robertson (25) $C$. paradoxa vem associado a processos patogênicos em plantas estressadas em palma de óleo.

Nas plantas inoculadas com ferimentos na ráquis, observaram-se sintomas externos, como lesões necróticas marrom escuro, no ponto de inoculação, ocorrendo por vezes a formação de um halo amarelado e exsudação de resina. Com o progresso da doença, verificaram-se folhas amareladas, que secavam e quebravam (Figura 1).

Resultados semelhantes foram observados por Robertson (25) quando testou a patogenicidade de Ceratocystis paradoxa em mudas de palma de óleo e verificou lesões necróticas de coloração marrom na ráquis e nas folhas apicais, se espalhando sobre a superfície da folha, seguido de seca e quebra. Alvarez et al. (1) observaram os sintomas em mudas de palma de óleo uma semana após a inoculação durante o teste de patogenicidade, com lesões necróticas castanhas e clorose que se estendiam por toda a folha. Verificou-se o apodrecimento dos tecidos internos com comprometimento de vasos condutores, o que explica a subsequente seca das folhas inoculadas. Segundo Alvarez et al. (1), quando submetidas a algum tipo de estresse, as plantas ficam mais predispostas à infecção por este fungo. O isolado de Thielaviopsis sp. foi patogênico nas duas cultivares de palma de óleo.

Mensuração do crescimento micelial e avaliações de características morfológicas

O fungo apresentou crescimento rápido sendo que, com $48 \mathrm{~h}$ após a repicagem, a colônia já ocupava toda a superfície da placa de Petri de $90 \mathrm{~mm}$. A VCM foi de 50,76 $\mathrm{mm} \mathrm{dia}^{-1}$. Observou-se durante 3 dias de crescimento, que a coloração variou, apresentando-se o micélio branco, entre os dois primeiros dias, e no terceiro dia a coloração negra. O isolado apresentou textura micelial aveludada com micélio ralo e aéreo (Figura 2).

$\mathrm{O}$ isolado apresentou abundante formação de conídios, sendo observados dois tipos, os endoconídios que são classificados como conídios primários, sendo asseptados, hialinos e retangulares, medindo 3,0-4,0 x 1,5-3,0 $\mu \mathrm{m}$; e conídios secundários, asseptados, amarronzados, oblongos a ovais, medindo 7,0-10,0 x 3,0-5,0 $\mu \mathrm{m}$; e os aleurioconídios, esféricos e lisos, de paredes espessas e marrons, medindo 5-7 × 5-7 $\mu \mathrm{m}$. As características morfológicas analisadas do fungo foram semelhantes às descritas por Mbenoun et al. (17) quando observaram o fungo Ceratocystis ethacetica em abacaxi, palma de óleo e cacau da região de Camarões na África (Figura 3).

O estudo sobre a classificação dos conídios apresentados neste trabalho é importante, uma vez que os conídios possuem funções na sobrevivência, dispersão e patogenicidade. Com a recente separação das espécies $T$. paradoxa e $T$. ethacetica, faz-se necessário alinhar a etiologia da podridão basal da palma de óleo no Brasil, até então atribuída ao fungo T. paradoxa. São escassos os trabalhos envolvendo a caracterização morfológica de T. ethacetica. Segundo Mbenoun et al. (17), as duas espécies têm características morfológicas semelhantes.

\section{Caracterização Molecular}

Foi construído o filograma a partir das amplificações e sequenciamento das regiões ITS e EF, para a comparação com sequências depositadas no GenBank (Figura 4). Observou-se que Thielaviopsis sp. foi alocado no mesmo grupo que outros isolados de T. ethacetica, com suporte de bootstrap de $100 \%$ por análise de máxima parcimônia. Portanto, de acordo com o sequenciamento da região ITS e EF, pode-se concluir que se trata da espécie T. ethacetica.

Em estudos baseados na análise de sequência de DNA e caracterização morfológica do complexo Ceratocystis paradoxa, o teleomorfo do fungo Thielaviopsis paradoxa (De Seynes) Hohn., foram reconhecidas cinco espécies do complexo, incluindo Ceratocystis paradoxa e Ceratocystis ethacetica, que apresentam linhagens

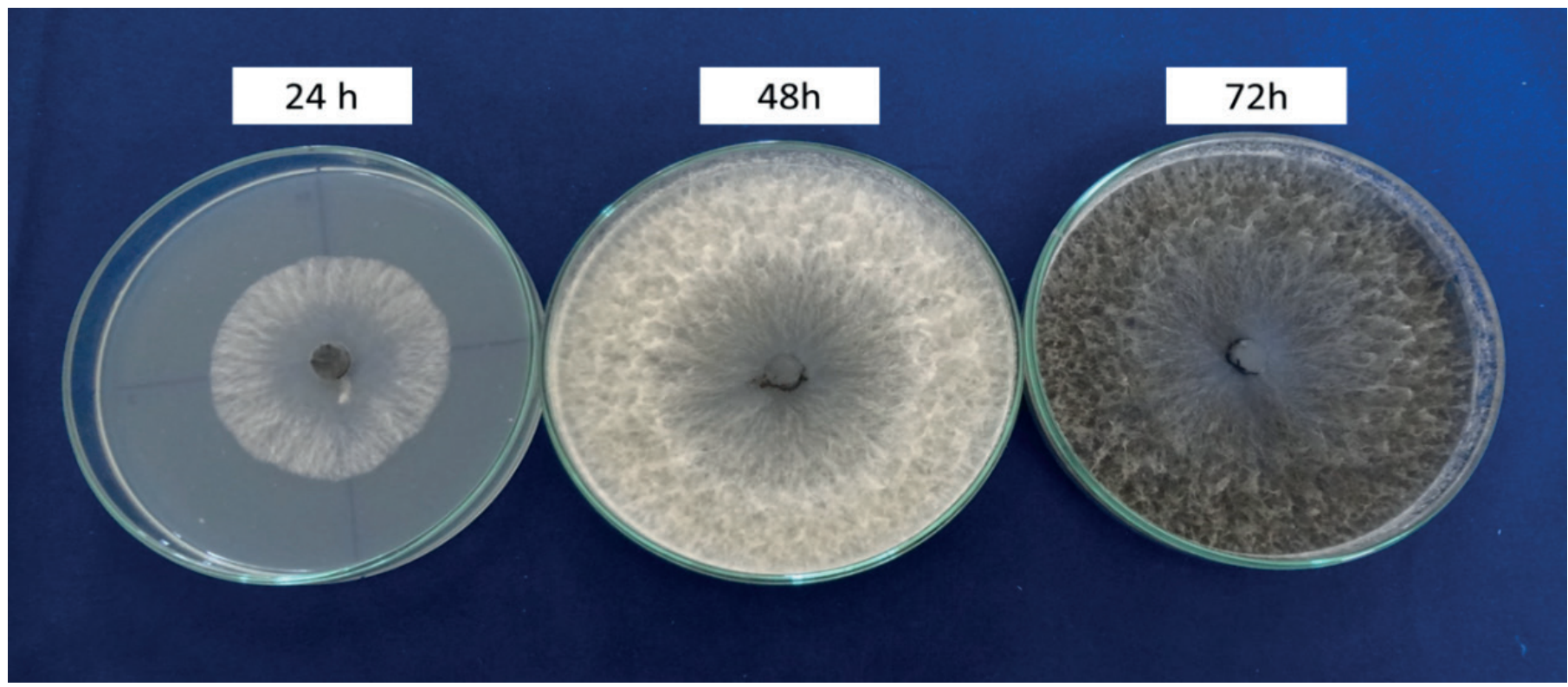

Figura 2. Crescimento da colônia em BDA e surgimento de coloração branca após 24 e 48 h e surgimento de coloração negra após 72 h à $28^{\circ} \mathrm{C}$. 

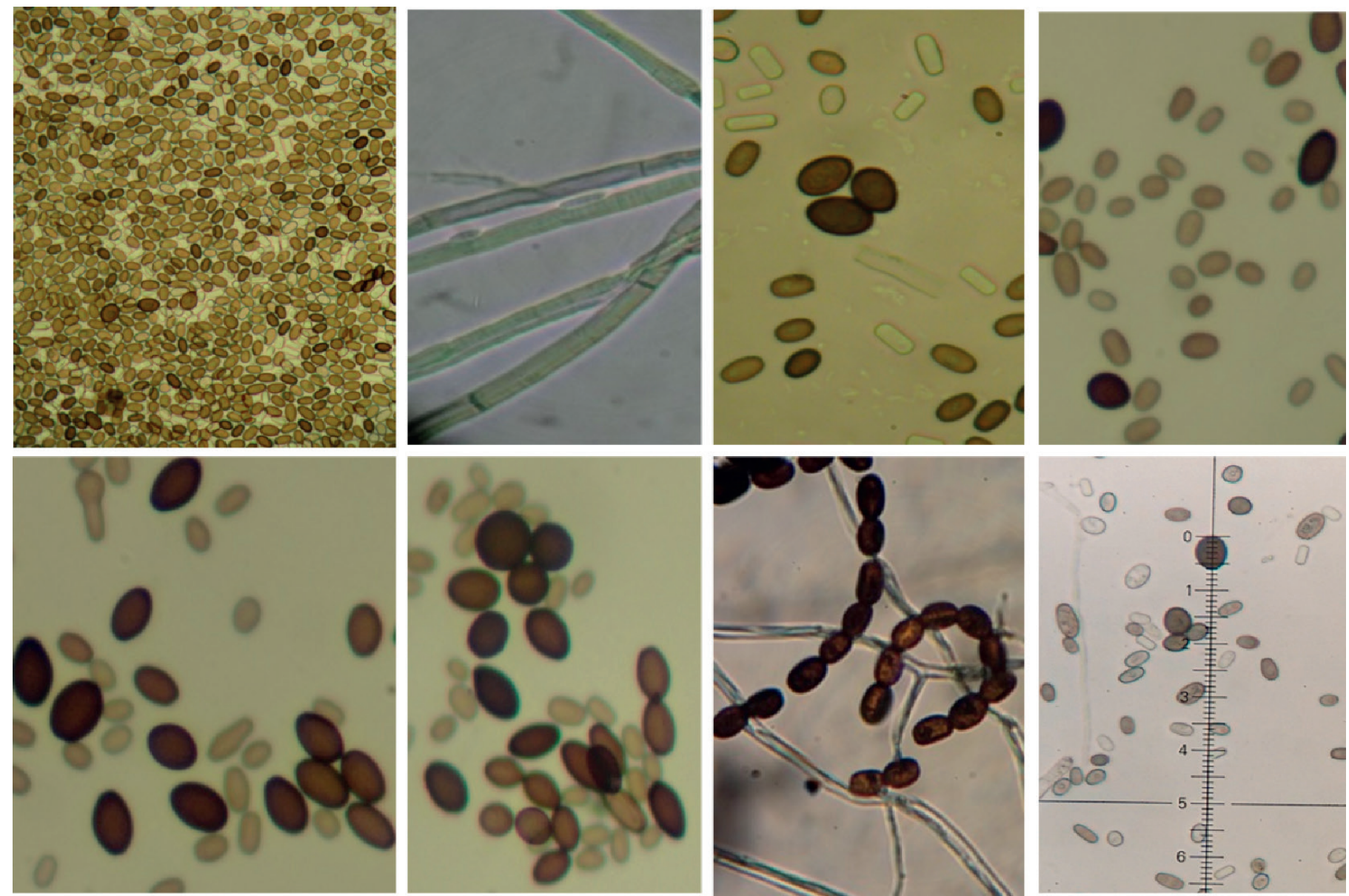

Figura 3. Estruturas reprodutivas: micélio, endoconídios (conídios primários e secundários) e aleurioconídios.

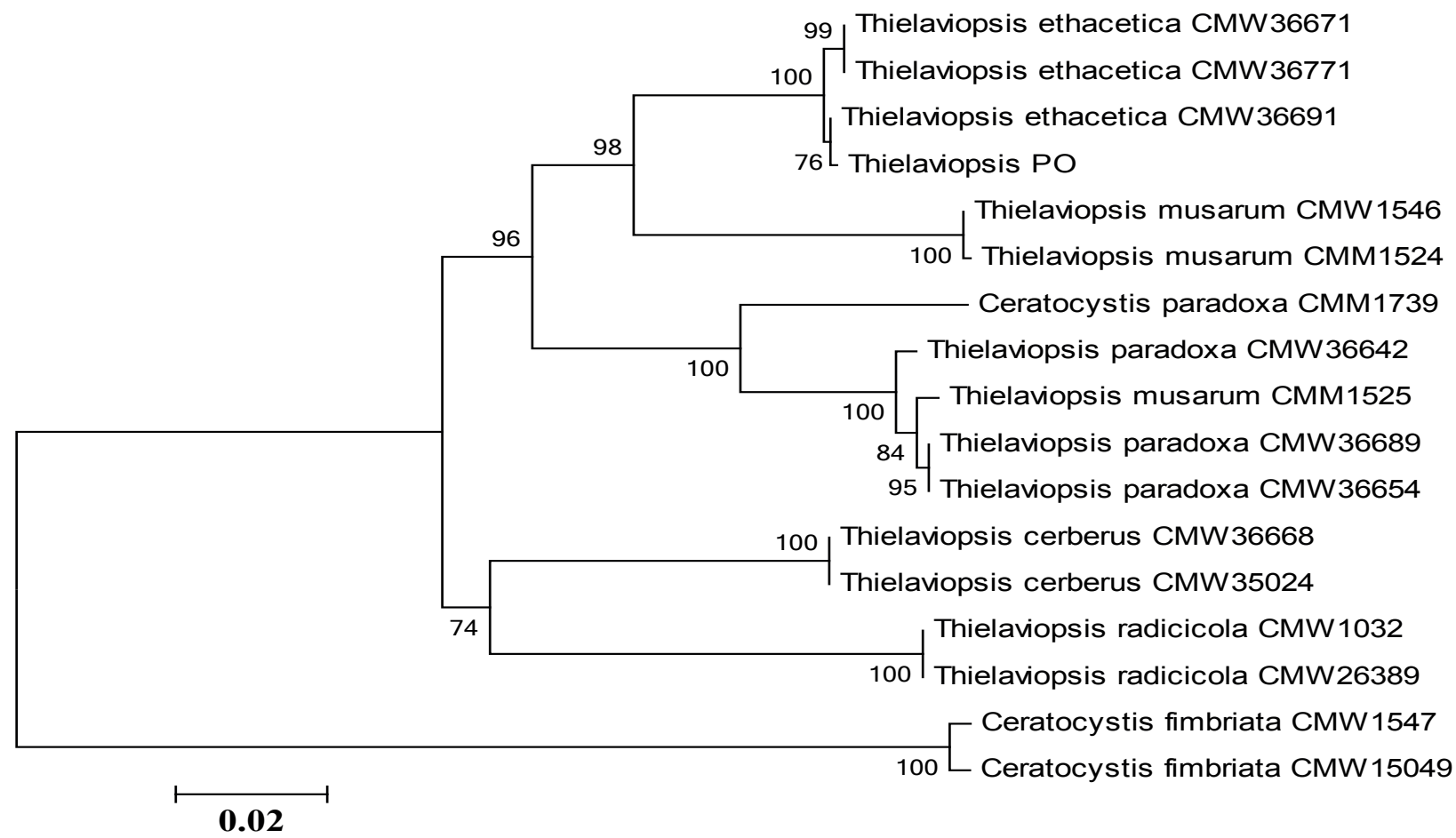

Figura 4. Filograma de máxima parcimônia das regiões ITS e EF de isolados de Thielaviopsis spp., com destaque para T. ethacetica. 
filogenéticas distintas e características morfológicas semelhantes dentro do mesmo complexo (17). Thielaviopsis ethacetica foi reiterado como um táxon distinto através de análises filogenéticas de DNA (17).

Mbenoun et al. (17) relataram alta diversidade genética entre os isolados de Thielaviopsis em Camarões. A correta identificação do agente etiológico da podridão basal da palma de óleo é de extrema importância para estudos da etiologia e na definição de medidas de controle, dentro do manejo integrado de doenças.

\section{REFERÊNCIAS}

1. Alvarez, A. E.; Llano, A. G.; John, B.; Loke, J. B.; Chacon, M. C. Characterization of Thielaviopsis paradoxa Isolates from Oil Palms in Colombia, Ecuador and Brazil. Journal of Phytopathology, Gottingen, v. 160, p. 690-700, 2012.

2. Alvindia, D. G.; Kobayashi, T.; Yaguchi, Y.; Natsuaki, K. Symptoms and the associated fungi of postharvest diseases on non-chemical bananas imported from the Philippines. Japanese Journal of Tropical Agriculture, Tokyo, v. 44, p. $87-93,2000$.

3. Boari, A. J.; Tremacoldi, C. R. Podridão do estipe causada por Thielaviopsis paradoxa em palma de óleo no Estado do Pará. Tropical Plant Pathology, Brasília, v. 37, 2012. Suplemento.

4. Borges, A. J.; Collicchio, E.; Campos, G. A. A cultura da palma de óleo (Elaeis guineenses Jacq.) no Brasil e no mundo: aspectos agronômicos e tecnológicos - uma revisão. Revista Liberato, Novo Hamburgo, v. 17, n. 27, p. 1-118, 2016.

5. Carvalho, E. A.; Coelho, I. L.; Tremacoldi, C. R.; Gomes Júnior, R. A. Fungos associados ao híbrido interespecífico da palma de óleo no Estado do Pará. Tropical Plant Pathology, Brasília, v. 36, p. 908, 2011. Suplemento.

6. Carvalho, E. A.; Santos, T. P. F. Doenças da palma de óleo no contexto da expansão do cultivo no Estado do Pará. Belém: Embrapa Amazônia Oriental, 2013. 19 p. (Documentos, 389).

7. Chapola, R. G. Controle da Podridão Abacaxi da cana-de-açúcar por meio da pulverização de fungicidas em mudas no sulco de plantio. 2010. Dissertação (Mestrado em Ciências) - Escola Superior de Agricultura "Luiz de Queiroz", Universidade de São Paulo, Piracicaba.

8. Chavez, M. F. Enfermedaes de la palma africana en Ecuador y su combate. Ecuador: INIAP (Instituto Nacional de Investigaciones Agropecuarias), Santo Domingo: Estación Experimental Santo Domingo,1986. Departamento de Fitopatologia. (Manual $n^{\circ} 8$ ).

9. Chia, G. S.; Lopes, R.; Cunha, R. N. V.; Rocha, R. N. C.; Lopes, M T. G. Repetibilidade da produção de cachos de híbridos interespecíficos entre o caiaué e o dendezeiro. Revista Acta Amazônica, Manaus, v. 39, p. 249-254, 2009.

10. Corley, R. H. V.; Tinker, P. B. The oil palm. 4. ed. Oxford: Blackwell, 2003. E-book. Disponível em: https://epdf.pub/the-oil-palm-world-agriculture-series.html. Acesso em: 10 mar. 2018.

11. De Beer, Z.W.; Duong, T. A.; Barnes, I.; Wingfield, B. D.; Wingfield, M. J. Redefining Ceratocystis and allied genera. Studies in Mycology, New York, v. 79, p. 187-219, 2014.

12. Ferrari, J. T. Podridão negra do abacaxi. Instituto Biológico, São Paulo, v. 71, p. 49-51, 2009. Divulgação Técnica.

13. Homma, A. Agroenergia: a entrada de um novo ciclo na Amazônia. In: Gomes Junior, R. A. (ed.). Bases técnicas para a cultura da palma de óleo integrado na unidade produtiva da agricultura familiar. Belém, Embrapa Amazônia Oriental, 2010. p. -5.

14. Hohnel, F. X. R. Zur kentniss einige fadenpilze. Hedwigia, Stuttgart, v. 43, p. 295-299, 1904.

15. Joshi, S. D.; Sanjay, D.; Baby, U. I.; Andal, A. K. A. Molecular characterization of Pestalotiopsis spp. associated with tea (Camellia sinensis) in southern India using RAPD and ISSR markers. Indian Journal of Biotechnology, India, v. 8, p. 377-383, 2009.

16. Kile, G. A. Plant diseases caused by species of Ceratocystis sensu stricto and Chalara. In: Wingfield, M. J.; Seifert, K.A.; Webber, J. F. (ed.). Ceratocystis and ophiostoma taxonomy, ecology, and pathogenicity. St. Paul: APS, 1993. p. 173-183.

17. Mbenoun, M.; De Beer, Z.W.; Wingfield, M. J. Reconsidering species boundaries in the Ceratocystis paradoxa complex, including a new species from oil palm and cacao in Cameroon. Mycologia, New York, v. 106, p. 757-784, 2014.

18. Moura, J. I. L.; Oliveira, L.; Luz, E. D. M. N.; Silva, S. D. V. M.; Santos, R. S. Weel associated to Gummosis in oil palm (Eleaes guineesnsis Jacq) in Brazil. Revista de Agricultura, Piracicaba, v. 88, p. 87-89, 2013.

19. Murphy, D. J. The future of oil palm as a major global crop: Opportunities and challenges. Journal of Oil Palm Research, Kajang, v. 26, n. 1, p. 1- 24, 2014.

20. Nelson, S. Stem bleeding of coconut palm. Manoa: Cooperative Extension Service, College of Tropical Agriculture and Human Resources, University of Hawaii at Manoa, 2005. (Plant Disease, 30). Disponível em: http://https:// www.ctahr.hawaii.edu/oc/freepubs/pdf/PD-30.pdf. Acesso em 06 ago. 2017.

21. Nieto, P. L. E. Incidencia de pudriciones de estipe de la palma de aceite (Elaeis guineensis Jacq.) em Colombia. Palmas, Bogotá, n. 6, 1995. Número especial.

22. Obidzinski, K.; Andriani, R.; Komarudin, H.; Andrianto, A. Environmental and social impacts of oil palm plantations and their implications for biofuel production in Indonesia. Ecology and Society, Wolfville, v. 17, p. 1-25, 2012.

23. Oliveira, J. S. F.; Carvalho, K. B. A.; Carvalho, E. A. Protocolo modificado para extração de DNA do gênero Pestalotiopsis. In: Congresso Brasileiro de Recursos Genéticos, 2, 2012, Belém. Anais. Editora Sociedade Brasileira de Recursos Genéticos, 2012. v. 1, p. 619-622.

24. Oliveira, J. A. Efeito do tratamento fungicida em sementes no controle de tombamento de plântulas de pepino (Cucumis sativas $\mathrm{L}$.) e pimentão (Capsicum annanum L.). 1999. 111 f. Dissertação (Mestrado em Fitossanidade) - Escola Superior de Agricultura de Lavras, Lavras.

25. Robertson, J. S. Dry basal rot, a new disease of oil palms caused by Ceratocystis paradoxa (Dade) Moreau. Transactions of the British Mycological, New York, v. 45, p. 475- 478, 1962.

26. Silva, J. C. Controle biológico da resinose do coqueiro. 2015. 92 f. Tese (Doutorado em Proteção de Plantas)-Universidade Federal de Alagoas, Maceió, Alagoas.

27. Tovar, J. P.; Nieto, P. E. N. Caracterización de las principales pudriciones de estipe de la palma de aceite (Elaeis guineensis Jacq.), en la Zona Norte de Colombia. Palmas, Bogotá, v. 19, p. 2, 1998.

28. Warwick, D. R. N.; Ferreira, J. M. S.; Passos, E. E. M. Ocorrência de resinose do estipe do coqueiro em Sergipe provocada por Chalara paradoxa. Fitopatologia Brasileira, Brasília, v. 29, p. 171, 2004. Suplemento.

29. Went, F. A. F. C. De ananasziekte van het suikerriet. Mededeelingen van het Proefstation West-Java, Utrecht, v. 5, p. 1-8, 1893. 